\title{
BOEKBESPREKINGS
}

Van der Walt, B. J. ca 1984: Ideologiese stryd in Suider-Afrika. Vlug vir die afgode. Potchefstroom: IRS, $159 \mathrm{p}$.

Die doel van hicrdie boek is om die verskillende ideologieë van SuidAfrika krities te beoordeel. Daarom poog die skrywers volgens B. J. van der Walt om in die bepaalde ideologieë in te kruip en te beskryf hoe dit van binne lyk. "Hulle wil eintlik aantoon dat 'n ideologie eintlik 'n draak is met baie koppe of 'n seekat met baie suigarms" (p. 2). Dit word gedoen met die wete dat "... geen sterfling - en dus ook die skrywers van hierdie boek nie - ideologiese besmetting kan vryspring nie en dat alleen God se Woord ons (kan) help om ideologieë reg te sien" (p 3). Myns insiens slaag die skrywers wel in mindere en meerdere mate daarin om hierdie uitgangspunt in hulle oortuigings te laat geid.

In die cerste artikel gee Elaine Botha 'n duidelike onderskeiding van begrippe wat in so 'n hespreking relevant is nl. Ideologie, Religie en Godsdiens. Sy behandel ook die verband "Filosofie en Ideologie" en sê op p 23: "Wanneer 'n filosofiese sisteem sy uitgangspunt en verklaringsgrond in iets in die werklikheid kies, is hy reeds baie duidelik ideologies gelaai". Hiermee vat sy die kern van die saak saam en is die standpunt ' $n$ baie handige beoordelingsnorm in die beoordeling van denkrigtings in Suid-Afrika aan alle kantc van die politieke en godsdienstige spektrum. Die meeste van die ander : ikrywers behandel, in hulle artikels in die bundel, ideologieë en ideologiese beïnvloe ding op verskeie gebiede binne hierdie raamwerk en wek dit die idee dat 'n fyn balans gehandhaaf word. Die artikel van Elaine Botha is daarom belangrik omdat sy fyn en duidelike begripsonderskeidinge daarstel.

Wat ook vermelding verdien is die artikels van Peet van Niekerk. Hy toon veral aan hoe ideologieë teen-ideologieë oproep en pas dit toe op die SuidAfrikaanse situasie met besondere verwysing na Wit en Swart nasionalisme. Sy uiteensetting van Kapitalisme en Sosialisme op p 32 is egter nie heeltemaal duidelik nie en dit is moeilik om sonder voorbchoud sy konklusie te onderskryf. Dit lui: Dit is duidelik dat 'n keuse tussen kapitalisme en sosialisme vir die Christen ' $n$ valse dilemma is en dat 'n derde weg gesoek moet word waarop die gedagte van rentmeesterskap in die ekonomiese lewe konkrete gestalte moet kry." Wat is daardie derde weg?

'n Ander gevaar van 'n ideologie word deur Jan du Plessis aangedui. Hy se: "Dit sit mense oogklappe aan, sodat hulle by die werklikheid verbykyk en dit nie kan raaksien nie." (p 68). Hierby kan ook die uitspraak van Pieter oe Klerk genoem word: "Ideologieë is dus in baie opsigte slegs middele in die hande van maghebbers om dis massas met beloftes van 'n toekomstige paradys aan hulle kant te kry. Tog het feitlik alle ideologter hulle oorsprong in die opregte strewes van leiers om 'n beter bedeling vir hulle mense te probeer bewerkstellig." (p 41). Die boodskap is duidelik: Wat begin as 'n opregte strewe na 'n beter bedeling vir mense word so maklik 'n fanatiese stryd waar. in realiteite geignoreer word en uiteindelik teen-ideologieë opgeroep word.

Die invloed van ideologiee op die taal en die massamedia word ook behandel terwyl Johan Snyman die aandag vestig op die "toekomsloosheid" van ideologiex. Dit klink na 'n teenstrydigheid omdat 'n ideologie juis gebore 
word uit die soeke na 'n beter toekoms vir mense. Maar die geskiedenis ondersteun Snyman in sy uilspraak (p 103) "En die nuwe orde neem telkens maar net die magsinstrumente van die ou orde op en draai dit teen die vorige bewindhebber. Die paradys van elke ideologie is die euforie van maguitoefening - 'n paradys vir die diktator en sy veiligheidpolisie" (p 103).

In sy geheel is die bundel 'n goeie bydrae van die IRS. Of die soms breedsprakige formuleringe van party artikels in almal se smaak sal val is te betwyfel. Maar die basies boodskap is goed tuisgebring: Ons moet op alle gebiede vlug vir die afgode van die ideologieë wat in Suid-Afrika aan die werk is. Die woord "vlug" is miskien eensydig en kan selfs negatief geinterpreteer word. In aansluiting by Theo van der Merwe sou 'n mens eerder kan pleit vir die wegwerk van die afgode. Sy uitspraak op p 85 is so raak dat dit ook aangehaal kan word as nog 'n waarheid wat die bundel hoogs aanbevelenswaardig maak. Hy sê: "Geen mens kan uiteraard die kwaad uit die wêreld wegdink of sonder meer ongedaan mak nie. Elkeen kan egter begin om dit uit die wêreld weg te werk. Groot dinge begin klein, soos eerbied vir eenduidige standaarde, vir 'n moraal wat die toets van die waarheid kan deurstaan, wat betroubaar en geloofwaardig vir alle partye is."

J. M. Vorster.

Eindred. M. Nel 1985: Kerkjeug antwoord. N.G. Kerkboekhandel Pretoria, 61 bladsye, R6,50.

Die tekort aan literatuur oor die kerklike bediening aan die jeug, veral by die Afrikaanse kerke, blyk uit die aanbevole literatuurlys aan die einde van hierdie boek. Daarom is 'n publikajie soos hierdie ' $n$ belangrike bydrae. Die bedoeling is om "tegelyk 'n antwoord van die kerkjeug en 'n antwoord van die kerk aan die jeug" te wees (Voorwoord).

Die antwoord van die kerkjeug word hoofsaaklik geformuleer aan die hand van 'n ondersoek deur die Instituut vir Toekomsstudies aan die P.U. vir C.H O. wat onder leiding van prof. Hentie Boshoff gedoen is vir die belydende $\mathrm{KJA}$ van die Ned. Geref. Kerk in Wes-Transvaal (1982). Daar word ook kennis geneem van 'n landswye ondersoek deur die Algemene Jeugkommissie van die Ned. Geref. Kerk na die emosionele en intellektuele behoeftes van jongmense (EIB-ondersoek in 1982).

Hoofstuk 1 gee 'n beeld van die kerklike jongmens van die tagtigerjare (prof. Boshoff), hoofstuk 2 bied 'n prinsipiële en praktiese tipering van die kerklike bediening aar die jongmens (dr. Malan Nel), hoofstuk 3 behandel kerklike jeugwerk se algemene organisatoriese toepassing (ds. Henk Gous) en hoofstuk 4 gaan in op die jeugarbeid in en deur die kerkjeugaksie (ds. Willie van Wyk). Veral die laaste twee hoofstukke is pertinent gerig op die bediening in die Ned. Geref. Kerk.

\section{Eerste hoofstuk}

Boshoff bied in hoofstuk 1 'n weergawe van die veranderde leef- en denkwereld van die jongmens van vandag tussen 17 en 25 jaar. Sy grondstelling is dat daar by die jongmens van vandag "'n skipbreuk van sekerhede" is. Volgens hom het die jongmens van die sestiger.- en begin sewentigerjare geleef 
in die tyd van sekerhede op o.a. politieke, ekonomiese en volkereverhoudingsgebiede. Die vraag is egter of dit nie dalk in daardie jare was wat die "skipbreuk" plaasgevind het en dat die huidige geslag jongmense bejig is "om aan wal te stap" nie? Is die huidige jongmens nie selfstandiger in sy denke, meer realisties in sy vrae en meer nugter in sy formulering van antwoorde nie?

'n Verdere opmerking moet gemaak word oor die jongmense wat in hierdie ondersoek en bevindinge ter sprake is. Hierdie boek is geskryf oor "die bediening van die kerk aan sy jeug" (Voorwoord). Die ondersoeke waarna verwys word, is ook gedoen onder jong lidmate van die kerk. Is die lidmate van die kérk sulke "skipbreukelinge"? Dit kan dalk nog veralgemenend van d'e kerklosse en onverankerde jongmens "op die straat" gesê word. Spruit die vrae wat die jongmens aan die kerklike bediening vra uit verwardheid (vgl. bl. 9), of is dit bloot ' $n$ vra na eerlike antwoorde - omdat geen mens (ook volwassenes) daarvan hou om met 'n kluitjie in die riet gestuur te word nie?

Hierdie vrae moet nie afdoen aan die handige gebruikswaarde van hierdie hoofstuk nie. Die tiperinge van die moderne mens word goed raakgevat as die opkoms van individualisme, die min-dinge absoluut-reg-of-verkeerd-gedagte, die eksistensiële sieninge en die opkoms van die gevoels- of ervaringsmens. Die praktiese implikasies hiervan vir die kerklike bediening aan die kerkjeug word duidelik aangedui.

Tweede hoofstuk

Byna die helfte van hierdie boek word afgestaan om in die tweede hoofstuk die kerklike bediening aan die jongmens uiteen te sit (deur dr. Malan Nel). Hy behandel eerstens drie onverhandelbare vertrekpunte (verbondsgesin, volwasse deel van die gemeente, Jesus Christus), dan agtereenvolgens die erediens, prediking en pastorale sorg. Koinonia word as 'n onderdeel van die crediens behandel (bl 28 e.v.). maar kon dalk beter tot sy reg gekom het as dit 'n selfstandige afdeling was.

Nel laat duidelik blyk dat hy 'n simpatieke kenner van die jeug is. Hy le tcreg klem op die eis dat die predikant eg moet wees en eerlik saam met die jeug "in die bootjie mnet klim" (bl. 38) sodat hy met opregte respek en waardering vir die persoon van die jongmens saam na die antwoord wat in Christus is te soek (bl. 39). Daarom beklemtoon Nel dit dat dit vir jeugarbeid te goedkoop is "om van die veilige wal van die rivier antwoorde te skreeu" (bl. 38) asof die volwassenes altyd al die antwoorde het (bl. 39).

Die grootste tekortkoming in hierdie hoofstuk is duidelike Skrifbegronding. Die kennis en insig van 'n jeugkenner is baie duidelik, maar die gesag van die eksplisiete Woord van God word gemis. Ter illustrasie word verwys na die behandeling van die aanbiddingsgebeure in die erediens (bl. 26-8). Dit word psigologies behandel met verwysinge na Oosterse meditasie (kontra) en na wat 'n Amerikaanse skrywer "by geleentheid" gese het (pro). Sou dit nie beter gewees het om aan te dui wat die Woord van God se nie?

Die waarde van hierdie hoofstuk is dat dit 'n oorsigtelike en kernagtige weergawe gee van dic belangrikste aspekte van jeugwerk in die kerk. Komende uit die pen van icmand wat ba' endervinding en insig op hierdie gebied het, is dit die moeite werd om daarvan kennis te neem. 


\section{Derde en vierde hoofstukke}

Hierdie twee hoofstukke is baie spesifiek gebaseer en gerig op die situasie van die Ned. Geref. Kerk en moet as sodan'g beskou word.

Ds. Henk Gous basseer hoofstuk 3 op die genoemde EIB ondersoek wat die Belydende KJA raak. Hy beklemtoon 'n gesellige atmosfeer, goeie doelgerigte beplanning en le erskap asook die samesnoering van belangegroepe as belangrike aspekte in die aanbieding van aktiwiteite vir die jeug (bl. 42-8). In hoofstuk 4 gee ds. Willie van Wyk 'n toepassing van die voorafgaande gegewens vir die Kerkjeugaksie van die Ned. Geref. Kerk (bl. 49-60).

Verskillende handige en praktiese wenke word in hierdie hoofstukke ge. gee wat deur enige kerk gebruik kan word in die beplanning van aktiwiteite en die bepaling van onderwerpe vir die jeug.

\section{Samevattend}

Die vraag of die boek in sy tweërlei doel geslaag het om 'n antwoord van die kerkjeug en aan die kerkjeug te wees kan nie sonder meer bevestigend beantwoord word nie. In die formulering van die jeug se antwoord is die jeugkenners meer aan die woord as die jeug self. Die stem van die jeug kom nie baie duidelik deırr nie. Die antwoord aan die jeug word gebied in 'n kerklike, strukturele gewaad en nie as 'n eksplisiet Skriftuurlike antwoord nie. Laasgenoemde feit is te betreur omdat die trant van die boek deurentyd is dat die jeug 'n antwoord uit die Skrif wil he - dit sou verrykend gewees het as hierdie boek 'n sprekende voorbeeld daarvan gewees het.

Nogtans, en met inagneming van bogenoemde, kan enige predikant of kerkraad baie nuttig van hierdie werk gebruik maak. Nie net vir jeugwerk nie, maar ook vir dir bediening in die algemeen, is hier kosbare gegewens. Die keurige tegniese afwerking gee 'n besondere kwaliteit aan die voorkoms van hierdie publikasie.

A G.S.V.

Barnard. A. C. (dr.) 1984: Ek is gedoop. N.G. Kerkboekhandel 110 p. R6.95.

Prof. Barnard skrywe met begrip oor die doopstryd wat die laaste aantal jarc weer woed, en ook oor die agtergronde daarvan. Hy be met reg dat die doop soos 'n "hefboom gebruik" (misbruik? J. J. v.d. W.) word "om mense uit hulle kerke uit te lig" $\mathrm{Hy}$ is goed vertroud met die beste en jongste literatuur en het daaruit ' $n$ baie goeie seleksie gemaak vir die nut van wie nie teologies opgelei is nie ("die gewone gelowige"). Hy gaan van die helc Skrif uit en wil nie "tekste op die klank af" gebruik nie. Die "groot Bybelse lyne en die gees en bedoeling van die Bybel" staan egter sleg; vas met bewyskrag in die stryd nadat behnorlike eksegese van tekste (in Skrifverband) gegee is. Sonder tekste het ons net 'n doopteologie wat 'n mens kragloos laat in dic stryd teen die wederdopers. Daarom waardeer ons die eksegetiese bewysmateriaal wat Barnard op verstaanbare wyse byeenbring (p. 62 en verder).

Tussen al die baie geskrifte in die jongste jare oor die doop, kan ook hierdie boekie vrugbaar gebruik word vir die goeie Gereformeerde opbou en stryd teen dwaalleer.

Jan J. v.d. Walt. 
Breman, C. 1985: Zending van de Nederlands Gereformeerde Kerken onder die Zulu's in Natal, Zuid-Afrika. V U Uitgeverij, Amsterdam 178 paginas Hierdie boek is 'n aangepaste uitgawe van 'n skripsie vir die doctorale eksamen in Teologie aan die Ryksuniversiteit te Utrecht.

Die titel van die boek is enigsins misleidend omdat dit die indruk wek dat die sendingwerk van die Nederlandse Gereformeerde Kerk (NGK) bespreek gaan word. Dit is egter op een faset toegepas, naamlike die begeerte van die sendelinge van genoemde kerk om 'n eie predikanteopleiding vir die Zulu's daar te stel. Sy het egter 'n deeglike beskrywing gegee van die histo riese agtergronde. Sy het egter nie voldoende gegewens oor die groci en ontwikkeling van die sendingwerk. self gegee nie, om van daaruit te kom tot 'n wetenskaplike beoordeling van die noodjaak al dan nie van eie predikanteopleiding vir die Zulu's.

In Hoofstuk 1 behandel sy die cendende kerke in Nederland en op welke wyse hulle tot uitsending gekom het. Sy toon duidelik aan dat die enigste moontlikheid wat daar was om sendingwerk in Suid Afrika te kom doen, geleë was in 'n ooreenkoms met die GKSA. Dit was as gevolg van die beleid van die owerheid. Die sendende kerk het ook hulle eie problematiek rondom saamwerkende of steunbiedende kerke. Die Kerk van Kampen staan baie sterk op die uitgangspunt dat dit die plaaslike kerk is wat moet sending doen Ander Kerke gee egter steun in dié verband.

Van die ander kerke is weer meer aangewys op samewerkende kerke wat tog ook mede-seggerskap en medeverantwoordelikheid dra. Hoofstuk 1 is insiggewend om die Nederlandse agtergrond en ontwikkeling te sien vir dic uitstuur en onderhouding van die sendelinge in Suid-Afrika.

In hoofstuk 2 gee sy 'n skets van die Gereformeerde Kerk in S.A. met 'n kort oorsig oor die onstaan van die NG en die Hervormde Kerk. Die onstaangeskiedenis van die GKSA word objektief weergegee en die houding van die kerk teenoor apartheid word simpatiek benader. Sy stel eintlik skrywers uit die GKS $\Lambda$ aan die woord om die saak te stel Dit is 'n gebalanseerde beskrywing van die historiese gebeure met begrip vir die situasie. Sy spreek waardering uit vir dit wat op sendingwetenskaplike terrein deur die die GKSA bereik i.s.

In Hoofstuk 3 behandel sy die ontstaan van die Hammanskraalse Teologie se skool. Weer eens is dit 'n objektiewe weergawe van feite sonder om die saak krities te ontleed. Wat sy wel in hierdie hoof stuk weergee is die siening van die Nederlandse sendelinge oor die HTS. sowel as gedagtes van sendelinge in die GKS $\Lambda$. Dip sieninge word weergegee, sonder om dit krities te ontleed. Daar word gesê dat die HTS te westers en 'n te hoë standaard hand. haaf. Die kritiek word ook uitgespreek dat te min van die dosente aan die HTS sendingervaring het.

Dit is na my mening die kern van die saak: Is die kritiek dat dic HTS te westers en te hoog is, geidig of nie. As dio skrwfster nie bloot berus het by 'n weergawe van standpunte nie, maar elke standpunt krities ontleed het. dan sou die studie meer geslaagd gewees het. Die opmerklike is dat die oordeel van die oudstudente en studente van die HTS anders is as die van sendelinge. Ook dit word nie in diepte ontleed nie.

In hoofstuk 4 behandel sy drie pogings van die Nederlandse sendelinge om 'n predikantopleiding vir die Zulu's daar te stel. Hulle behoeftes daaraan 
is gegrond in oa. die te Westerse Hammanskraal, die feit dat die studente uit hulle milieu weggeneem word en dat die enkele pogings om wel iemand na Hammanskraal te stuur nie geslaag het nie. Daar is gepoog om tot die ideaal te kom in samewerking met die GKSA aanvanklik, en die laaste poging in samewerking met die Sinode Middellande. Opmerklik is dat daar van dis Sinode Middellande 'n behoefte beskryf word aan 'n eie teologiese skool met eie beheer en toesig. Die verskil tussen die sendeling en die deputate van die Sinode Middellande kom daarop neer dat die sendeling 'n meer prakties gerigte kursus vir die Zulu wil hê, teenoor die meer teoreties gerigte kursus van die deputate van die Sinode Middellande vir alle kerke in die Sinode. Die uit slag van hierdie samewerking is nog nie bekend nie, omdat die Sinode Middellande DV September 1985 sit en dan eers die saak sal behandel.

In hoofstuk 5 word haar eindkonklusie oor die saak van predikantopleiding gegee. Haar konklusie gee sy met omsigtigheid omdat dit 'n uiters komplekse saak is waarin twee wêrelde mekaar ontmoet: Nederlandse sendeling op SuidAfrikaanse bodem. Afgesien van dié twee wêrelde is daar volgens Breman ook nog die situasie van 'n eerste en derde wêreld in Suid-Afrika met die rasseproblematiek wat teenwoordig 'n groot rol speel. Sy erken dat daar ook verskil is in die swarte se ontwikkelingspeil soos byvoorbeeld in 'n stad soos Soweto en die plattelandse gebied van Natal waar dié sendelinge werksaam is. Dit kan lei tot botsing vari die waardering oor die HTS. Die ontwikkelde afgestudeerde predikante van die HTS het waardering vir die HTS met sy intellektuele en hoë wetenskaplike standaard. Daarteenoor is daar veral sen delinge wat die opleiding van HTS ongeskik ag vir die werklike behoefte van die jong kerke. Sy steun hierin ook op die siening van Sundkler en Krizinger.

Sy voel dat daar wel 'n noodsaak bestaan vir opleiding in Natal soo : deur die sendelinge voorgestel, en motiveer dat daar in 'n land soos Suid-Afrika waar daar wel 'n eerste- en derdewereld situasie voorkom, ruimte is vir 'n meer wetenskaplike opgeleide predikant, sowel as vir 'n meer prakties opgeleide predikant. Sy gebruik ook as motivering vir haar saak die ontwikkeling van die HTS vanaf Dube tot vandag, sowel ook die opleiding te Burgersdorp tot vandag aan die Potchefstroomse Teologiese skool. Sy noem die moontlikheid van 'n latere fase in die opleiding dat studente van Natal en HTS wel kan wissel om by die een opleiding te kry wat meer akademies en by die' ander meer prakties is.

My probleem hiermee is dat die ondertoon daarop dui dat predikanteopleiding gesien word as 'n instituut of skool naas die kerk. Die sendeling besluit wat is nodig vir die kerke en bied dit aan. Daarom ook dat die vergelyking met die ontwikkeling van die Potchefstroomse Teologiese skool vanaf Burgersdorp tot vandag toe nie geldig is nie, omdat dit uit die kerk gegroei het Opleiding van predikante is ' $n$ saak van die kerk volgens art 2 en 18 van die Kerkorde. Daarom ook dat die kerk moet toesig hou oor en beroep vir die opleiding. Verder word daar te dikwels 'n onderskeid gemaak tussen 'n predikant en 'n teoloog asof dil twee verskillende goed is. 'n Predikant moet 'n teoloog wees, en 'n teoloog wat nie 'n predikant is, nie, is nie meer gebind aan die diens in die kerk nie en kan so vervreem raak van kerk en belydenis.

Wat haar konklusic oor HTS betref, die volgende: Breman voel dat daar wel voortgegaan moet word met die opleiding van teoloë, behalwe as die HTS aan die TSP oorgegee word; of anders dat aan die HTS sendelinge opgelei 
word vir alle rasse en aan die TSP gemeentepredikante opgelei word vir alle rasse. Laasgenoemde stelling bly 'n vraag in haar konklusie. Ek wil hierdie opmerking maak dat regdeur die werk daar 'n te groot onderskeid gemaak word tussen sending en gemeentepredikant. Dit is tog immers 'n taak van die kerk om sending te doen Die kerk wat sy eie opbou verwaarloos terwille van sending is nie meer kerk nie, dieselfde geld ook vir 'n kerk wat eie opbou belangriker maak as sending. Verder is die situasie in Suid-Afrika (elders seker ook) dat elke gemeente in 'n sending situasie is. Waar sending gedoen word, kom daar ook gemeentestigting. Die opdrag in Matt 28 is: "... en leer hulle om alles te onderhou wat ek julle beveel het".

Dit is jammer dat Breman nie die besware teen die HTS beter ontleed nie. Die vraag kan tereg gevra word of dit geldige besware is: Is die opleiding aan die HTS te westers en te hoog? Waaraan is die uitsprake van die kritici van die HTS gemeet? Enkele probleemgevalle met van die afgestudeerde predikante? Of die groot tekort aan predikante veral in die kleinere gemeentès, eintlik wyksgemeentes soos by die werk van die Natalse sendelinge? Is die oplossing nie om art 8 var die KO te gebruik nie, of soos dit wel gebeur dat die evangeliste dic reg ontvang om wel sakramente te bedien nie? Dit is jammer dat sy dié reëling by die sendelinge van Kampen nie volledig bespreck dat die evangeliste wel die reg het om sakramente te bedien nie.

Oor die geldigheid van die kritiek teen die HTS, is dit moeilik om 'n wetenskaplike antwoord daarop te gee sonder diepgaande studie. Ek ken predikante wat daar opgelei is, wat waardevolle werk doen. Wat in gedagte gehou moet word, is dat die Westerse kultuur met sy tegnologiese ontwikkeling dominant is. Daarom is dit noodsaaklik dat predikante opgelei word om die gemeente te lei om sinvol in die veranderde wêreld as die sout en die lig op te tree. Nêrens in die werk word die begrip "Westers" duideliker omlyn en verklaar nie. Dieselfde geld ook vir die begrip "'n meer Afrika gerigte Teologie". Teologie moet immers Bybels gefundeerd wees. Dit is uiters noodsaaklik dat die Kerke in Sinodes Middellande en Soutpansberg meer betrokke moet raak en inspraak moet beoefen in die opleiding van hulle predikante. Die kerke kan byvoorbeeld self dosente beroep en by die opleiding aanbied. Daar moet ook 'n oplossing gevind word vir die groot tekort aan predikante in die kerke en die finansiële afhanklikbeid van die kerke.

Breman bied 'n waardevolle werk en elkeen wat te doen het met predikanteopleiding vir die jongkerk moet dit lees. Daar moet oor die hele toekoms van die opleiding van predikante besin word, want indien die HTS "ons skool vir hulle" moet wees, skep dit 'n moeilike situasie.

Sarel v. d. Merwe.

\section{BOEKAANKONDIGINGS}

Hoek, J. 1981. Daniël Colonius (1566-1635): Theoloog tursen reformatie en orthodoxie. Huizen N H: J Bout en Zonen. 223 bll. Prys onbekend.

In hierdie proefskrif gee die hervormde (Gereformeerde Bond!) dr Hoek aandag aan 'n (vandag) redelik onbekende predikant en teoloog uit die pe- 
riode van die na-reformatoriese ortodokse (sewentiende eeu) genaamd Daniël Colonius (Daniêl de Cologne). Dit is 'n lewensbeskrywing waarin Colonius se jeug en studietyd, sy predikant- en doseerwerk, sy werk op die beroemde sinode van Dordrecht en sy dogmatiese werk De Analysis Paraphrastica ('n parafrase van Calvyn se Institusie) ondersoek en beskryf word $\mathrm{Al}$ is daar tenden e van skolastiek in sy denke, was sy aansluiting by Calvyn tog veels te sterk om hom as skolartikus te tipeer.

Besonder boeiend is die gedeelte wat handel oor Colonius se werk op dic Sinode van Dordrecht, veral tov die uitverkiesingsieer (99-127). Hy was leier van die Waalse afvaardiging wat help bydra het tot die "milde klimaat van de Canones". "De positie van de meest consequent doordenkende en daardoor extreme calvinisten, de supralap ariërs, werd door hen afgewezen" (127). Hoek slaag daarin om deur te dring tot die diepste intensies van Arminius om sodoende sy krag en swakheid bloot te lê. Hy wys ook daarop hoedat daar deur ander foutiewelik van Calvyn se uitverkiesingsleer wegbeweeg is (Beza).

Hoek het ons hicitories dogmatiese literatuur verryk deur op 'n nougesette en verantwoorde wyse 'n besondere teoloog aan die vergetelheid te ontruk Vir elkeen wat veral in die na-reformatoriese ortodokse teologie belangstel, lewer hierdie boek 'n skat van informasie.

J. H. van Wyk.

\section{BOEKE, ON'TVANG VIR BESPREKING}

J H Barkhuizen 1985: CARMEN CHRISTIANUM, 'n Inleiding tot dic GricksChristelike Himnografie van die eerste ses eeue. NG Kerkbockhandel, Posbus 245, Pretoria. Prys R22 50.

Jansie van der Walt 1985: CALVYN AND HIS TIMES. IRS PU vir CIIO F2 $\mathrm{Nr}$ 32. Prys R7.50

Frnst $R$ Wendland ^985: LANGUAGE, SOCIETY, AND BIBLE TRANSLATION With special reference to the style ahd structure of segments of direct speech in the Scriptures. Bible Socicty of South Africa. Prys 12700.

Rev. Stuart Fowler 1985: THE WORD OF GOD IRS PU vir CHO F2 Nr 33. Prys R4.00

J P Louw 1985: LEXICOGRAPHY AND TRANSLATION. With special reference to Bible Translation. Bible Society of South Africa. Prys 127.00

Eugene A Nida 1984: SIGNS, SENSE, TRANSLATION. Bible Socicty of South Africa. Prys R7.00.

Rev. Stuart Fowler 1985: BIBLICAL STUDIES IN THE GOSIEL $A$ ND SOCIETY. IRS PU vir CHO F2 Nr 34. Pry.j R7 50.

Idem: THE WORD OF GOD, R4.00.

Wyle prof. J A van Wyk: WHAT WE BELIFVE. NG Kerkbockhandel, Posbus 245, Pretoria. Prys R7.25.

J J van Rensburg: NIF DEUR GEWELD. NG Kerkboekhandel, Posbus 245, Pre-

E P J Kleynhans 1985: GEREFORMEERDE KERKREG Deel 3 NG Kerkboekhandel, Posbus 245, Pretoria. R14.75.

toria. $\mathbf{R 5} 50$. 